\title{
Multivariate analysis of heavy metals content of beef from Soroti, Uganda
}

Keneth Iceland Kasozi ( $\sim$ kicelandy@gmail.com )

Busitema University https://orcid.org/0000-0002-5763-7964

Eric Oloya Otim

Purdue University Northwest

Justine Ekou

Busitema University

Kevin Matama

Kampala International University - Western Campus

Gerald Zirintunda

Busitema University

Emmanuel Tiyo Ayikobua

Soroti University

Andrew Tamale

Makerere University

\section{Regan Mujinya}

Kampala International University - Western Campus

Roua S. Baty

Taif University College of Science

Ashraf Albrakati

Taif University Faculty of Medicine

\section{Gaber El-Saber Batiha}

Damanhour University Faculty of Veterinary Medicine

\section{Ochan Otim}

University of California Los Angeles

\section{Research Article}

Keywords: Beef contamination, heavy metals, food safety, Soroti, Uganda

Posted Date: March 1st, 2021

DOI: https://doi.org/10.21203/rs.3.rs-289141/v1

License: (c) (i) This work is licensed under a Creative Commons Attribution 4.0 International License. Read Full License 


\section{Abstract}

Information about food hygiene and quality in the sub-Saharan African countries remains scarce at a time when many of their citizenry are beginning to acquire the much coveted middle income status. Compounding this are challenges linked to monitoring the safety of food produced by such lucrative industries as the beef industry on a continuous basis. The objective of the study was to begin some how the process of encouraging changes to the status quo and showing by example how a start in that direction might look like. Using heavy metal contents of representative beef samples from butcheries in Soroti, Uganda typical of a sub-Saharan country, we demonstrate how relationships and common sources of metals could be identified among samples in a multivariate space. Beef samples from 40 sites were analyzed by atomic absorption spectrometry for iron (Fe), zinc (Zn), nickel (Ni), chromium (Cr), lead (Pb), copper (Cu), cobalt (Co) and cadmium (Cd). The study showed that all beef samples contained these metals, the extent of which were in the order: Fe > $\mathrm{Zn}>>\mathrm{Ni}, \mathrm{Cr}>\mathrm{Pb}>\mathrm{Cu}, \mathrm{Co}>\mathrm{Cd}$. By correlation analysis, the pairs $\mathrm{Ni}$ and $\mathrm{Cr}$, $\mathrm{Cd}$ and $\mathrm{Co}, \mathrm{Ni}$ and $\mathrm{Fe}$ or $\mathrm{Cr}$ and Fe were most likely coming from the same sources. We also found that there are at least three distinct characteristics of beef consumed in Soroti, a distinction perhaps arising from three major categories of feedlots used to raise donor cattle. The incremental risk of children or adults developing cancer over a lifetime was estimated and found to fall into three categories, two of which are separately explained by the presence of $\mathrm{Cr}$ or Ni. The sources of these metals remain a matter of speculation on our part. More studies are needed to determine these sources and to understand the nature of cancer risk in the three categories of beef identified here.

\section{Introduction}

Food contamination in developing countries, sources of which range from food-borne biologicals and physical agents in food to chemical contaminants, is a major public health concern (Grace, 2015). In a country such as Uganda, heavy metals (defined as any metal that can induce toxicity in living systems regardless of atomic mass; Kamunda et al., 2016; Nkwunonwo et al., 2020; Singh et al., 2011)) originating from water, soil, food containment methods and particulates in the air (Anna et al., 2019; Kamunda et al., 2016; Kasozi et al., 2019; Yabe et al., 2010) are the causes of anxiety. Beef contamination is particularly a serious problem in the sub-Saharan region of Africa because of the loosely regulated manners in which donor animals are raised and how their carcasses are handled. For example, roasted meat sold on street walks in Kampala (Uganda) was shown to be heavily contaminated with lead (Pb), arsenic (As), cadmium (Cd), chromium $(\mathrm{Cr})$, copper (Cu), zinc ( $\mathrm{Zn}$ ) and iron (Fe) (Bamuwamye et al., 2015). In Nigeria and Ghana, beef, mutton, caprine, pork and chicken were found to contain $\mathrm{Cd}, \mathrm{Cr}, \mathrm{Cu}, \mathrm{Fe}, \mathrm{Pb}, \mathrm{Zn}$ or manganese $(\mathrm{Mn})$ at times above the recommended levels by international standards (Nkansah \& Ansah, 2014; Odoh et al., 2016). Confounding this public health concern is the inability to acquire the necessary capacity to remove or treat heavy metal toxicity, more so during this time when the eating habits of most sub-Saharan African families are changing in line with an increase in family income. It goes therefore without saying that without fully understanding the health risk attributed to food contamination in Africa, an impending health hazard might be on the verge of emerging.

Our goal in this study is, in part, to assemble statistical tools easily accessible to poor countries in Africa for analyzing contamination data irrespective of how the data were collected. The premises here is that some data is better than the status quo in informing food safety policies. At this time, most of the data available in Africa are collected using instruments with low precision detection limits, yielding subsequently unreliable results.

In this second of a two-part study (Kasozi et al., 2021), we particularly address - by way of example - the incremental lifetime cancer risk (ILCR) of consuming beef from Soroti District, Uganda with the aid of multivariate statistical tools. ILCR in our context represents the potential cancer risks of being exposed orally to heavy metals in beef. In general practice, the numerical range of acceptable risks is set between $10^{-6}$ and $10^{-4}$ (US EPA, 2001). Risk values above $10^{-4}$ are considered a cause of concern, hence requiring mitigation (US EPA, 2008). For this study, we asked whether it is possible to distinguish potential drivers of cancer risk in a community from a low-resolution set of data. This question arises from 
our belief that data obtained by insensitive instruments have, at the minimum, intrinsic values helpful to regulators in Africa.

The primary focus of the study was to determine the amounts of $\mathrm{Cu}, \mathrm{Zn}, \mathrm{Pb}, \mathrm{Cd}, \mathrm{Co}, \mathrm{Fe}, \mathrm{Ni}$ and $\mathrm{Cr}$ in beef from an array of sources around Soroti, a metropolitan area of Uganda. $\mathrm{Zn}, \mathrm{Cu}$ and $\mathrm{Pb}$, for example, are potentially three of the most common heavy metals in vehicular emissions in the country. Particulates of these metals can easily settle on beef sold in roadside stalls. $\mathrm{Ni}$ and $\mathrm{Cd}$ are freely disposed of, or burned, in used $\mathrm{Ni} / \mathrm{Cd}$-containing batteries in the environment (Kasozi et al., 2018). In our selection of elements to study, $\mathrm{Ni}$ and $\mathrm{Cr}$ were also candidates because both occur naturally in soil and water with the capacity to bioaccumulate in cattle raised for beef. Furthermore, both are known human carcinogens (Anon, 1990; Chen et al., 2019; Kim et al., 2015; USEPA, 1998).

Lead $(\mathrm{Pb})$, a known carcinogen and naturally occurring metal in the Earth's crust, is commonly attributed to anthropogenic activities. At this time, $\mathrm{Pb}, \mathrm{Cd}, \mathrm{Co}$ and $\mathrm{Ni}$ are 2nd, 7th, 52nd, and 58th on the US Agency for Toxic Substances and Disease Registry priority list of 275 substances that pose the most significant potential threat to human health (ATSDR, 2019). It was also likely that where $\mathrm{Pb}$ contamination is found in Uganda, there is likely to be $\mathrm{Cr}$ contamination as well (Otim et al., 2019a). Of the eight metals studied here, only $\mathrm{Pb}$ and $\mathrm{Cd}$ appear to be regulated in cattle feed in Uganda (maximum 5.0 $\mathrm{mg} / \mathrm{kg}$ and $0.5 \mathrm{mg} / \mathrm{kg}$, respectively (Uganda National Bureau of Standards, 2018). The lack of appropriate guidelines for heavy metals in foods consumed in Uganda and Africa at large predisposes consumers to a serious health risk.

The use of 'contamination' in this study implies high level of an element in a beef sample which could have a detrimental health effect on consumers. That being said, high levels of certain essential elements such as Fe, Zn and Cu would not be regarded has contamination unless a toxicity effect was ascertain for the said level.

\section{Materials And Methods \\ 2.1. Sampling area}

The vegetation of the metropolitan area of Soroti is best described as savannah. And for an area covering about $26 \mathrm{~km}^{2}$ $\left(10 \mathrm{mi}^{2}\right.$ ) (https://www.calcmaps.com/map-area/; https://www.google.com/maps/place/Soroti), the Uganda Bureau of Statistics estimated the mid-year population of Soroti to be about 60,900 in 2020 (https://www.citypopulation.de/en/uganda/cities/). The soil is classified as plinthosols because of excess iron and aluminium oxides which gives it a red color (Kaaya et al. 1994; Kimera et al. 2018). Cattle in this area graze outside on the savannah vegetation freely.

\subsection{Sampling, sample preparation and instrumental analysis}

Approximately $200 \mathrm{~g}$ each of 40 beef samples was collected into sterile plastic bottles maintained at $4^{\circ} \mathrm{C}$ from local supplies and processed as described earlier (Alam et al., 2018; Kasozi et al., 2018). In brief, $1 \mathrm{~g}$ of each sample was mixed with $20 \mathrm{~mL}$ of nitric acid and $4 \mathrm{~mL}$ of analytical grade perchloric acid and digested on a hot plate until the final volume was $4 \mathrm{~mL}$. The solution was then cooled and filtered, and the final volume was adjusted to $50 \mathrm{~mL}$ with deionized water. The concentration of these eight heavy metals in each beef extract was determined by atomic absorption spectrophotometry (AAS, PerkinElmer 2380) at the following respective wavelengths (nm): $\mathrm{Pb}, 217.0 ; \mathrm{Cr}, 357.9 ; \mathrm{Cu}, 324.9$; $\mathrm{Zn}, 213.9 ; \mathrm{Cd}, 228.8 ; \mathrm{Co}, 240.7 ; \mathrm{Fe}, 248.3 ; \mathrm{Ni}, 323.0$ ). Four (4) calibration standard solutions at the 0.0, 0.5, 2.0 and $5.0 \mathrm{ppm}$ levels were used to generate a linear absorbance range for converting absorbance into concentration. Inline with standard practice in this field, blank (solvent) and laboratory control samples were analyzed as well for quality assurance.

Of note, information on sources of donor animals was not available at sample collection due to logistical reasons. This would have helped narrow down sources of contaminating metals. Second, the need to carry out sample size calculation was not warranted because of the exploratory nature of this study and the unlikeliness of detecting metals in beef 
samples by chance using a well-calibrated atomic absorption spectrophotometer when there is none. Finally, to our knowledge, there have been no mineral mining or such activities prior to and during sample collection in the sampling area. Results are reported in wet-weight.

\subsection{ILCR determination and statistical analysis}

The protocol we used to convert raw concentration values to incremental lifetime cancer risk (ILCR) has been published elsewhere (Kasozi et al., 2018). For statistical analysis, data were imported into PAST software (Hammer et al., 2001) for principal component analysis (PCA) (Gergen \& Harmanescu, 2012; Gewers et al., 2018) and into R (R Core Team, 2019) for cluster analysis (CA) (Boutros \& Okey, 2005) and assessing distribution by boxplots (Beniamini, 1988; Wiley \& Pace, 2015). The application of CA and PCA, and similar exploratory techniques, in the food industry in this way is not new (Boutros \& Okey, 2005; Fotakis \& Zervou, 2016; Gergen \& Harmanescu, 2012; Gewers et al., 2018; Zwick \& Velicer, 1982) and should be encouraged in sub-Saharan Africa. Divisive hierarchical cluster analysis (DIANA) was used to identify large clusters in a concentration dataset. A tree-based format was used to display the results. Variables were mostly scaled to make metal concentrations comparable across samples. They were either log-transformed or standardized to have a mean of zero and a standard deviation of one. To measure dissimilarity between any two clusters of the tree, Ward's minimum variance method was applied to log-transformed data. Ward's method (as opposed to others) minimizes the total within-cluster variance.

\section{Results And Discussion}

\subsection{Descriptive analysis}

Forty (40) beef samples collected from Soroti District of Uganda were studied here (i) to understand for the first time the nature and extent of beef contamination by heavy metals ( $\mathrm{Cu}, \mathrm{Zn}, \mathrm{Pb}, \mathrm{Cd}, \mathrm{Co}, \mathrm{Fe}, \mathrm{Ni}$ and $\mathrm{Cr}$ ) in this area and (ii) to assess the importance of four of the metals $(\mathrm{Pb}, \mathrm{Cd}, \mathrm{Ni}$ and $\mathrm{Cr}$ ) in the incremental risk of developing cancer over a lifetime in Soroti. The results of our study under these two goals are presented separately below. Descriptively, all beef samples studied were found to contain all eight heavy metals listed above, albeit with extensive variability (Table 1). A casual inspection of the results shows that Fe was the most abundant in samples of the eight metals, followed by $\mathrm{Zn}$ and at approximately the same levels $\mathrm{Ni}$ and $\mathrm{Cr}$; the least abundant was $\mathrm{Cd}$. Detected at $\leq 5 \mathrm{ppm}$ (approximately five times higher than $\mathrm{Cd}$ ) were $\mathrm{Cu}$, Co and $\mathrm{Pb}$. 
Table 1

Concentrations of eight heavy metals (ppm) in 40 beef samples collected from Soroti, Uganda.

\begin{tabular}{|c|c|c|c|c|c|c|c|c|}
\hline Sample ID & $\mathrm{Cu}$ & $\mathrm{Zn}$ & $\mathrm{Pb}$ & Cd & Co & $\mathrm{Fe}$ & $\mathrm{Ni}$ & $\mathrm{Cr}$ \\
\hline 1 & 2.8 & 46 & 10.9 & 0.8 & 2.6 & 196 & 25 & 25 \\
\hline 2 & 1.3 & 28 & 5.0 & 0.3 & 1.3 & 111 & 15 & 17 \\
\hline 3 & 1.8 & 40 & 4.3 & 0.1 & 1.3 & 163 & 20 & 28 \\
\hline 4 & 1.6 & 36 & 4.7 & 0.3 & 1.3 & 167 & 16 & 21 \\
\hline 5 & 1.4 & 27 & 5.0 & 0.3 & 1.7 & 177 & 23 & 29 \\
\hline 6 & 1.2 & 51 & 5.3 & 0.3 & 1.6 & 167 & 21 & 26 \\
\hline 7 & 3.0 & 48 & 4.6 & 0.4 & 1.9 & 220 & 27 & 36 \\
\hline 8 & 1.5 & 43 & 4.1 & 0.1 & 1.1 & 129 & 16 & 26 \\
\hline 9 & 1.4 & 75 & 5.4 & 0.4 & 1.7 & 175 & 22 & 30 \\
\hline 10 & 1.1 & 46 & 5.7 & 0.1 & 0.8 & 89 & 12 & 17 \\
\hline 11 & 1.6 & 36 & 7.4 & 0.9 & 2.6 & 188 & 26 & 30 \\
\hline 12 & 2.1 & 38 & 8.4 & 0.5 & 2.2 & 1511 & 23 & 24 \\
\hline 13 & 2.3 & 79 & 2.4 & 0.3 & 2.0 & 185 & 24 & 31 \\
\hline 14 & 1.8 & 37 & 5.3 & 0.4 & 1.9 & 154 & 19 & 23 \\
\hline 15 & 1.3 & 38 & 4.3 & 0.3 & 1.6 & 127 & 15 & 18 \\
\hline 16 & 1.8 & 77 & 8.6 & 1.0 & 3.0 & 139 & 18 & 20 \\
\hline 17 & 0.8 & 28 & 8.1 & 0.6 & 2.2 & 107 & 14 & 16 \\
\hline 18 & 1.1 & 35 & 6.9 & 0.4 & 1.3 & 77 & 9 & 12 \\
\hline 19 & 0.8 & 53 & 7.6 & 0.3 & 1.1 & 73 & 6 & 7 \\
\hline 20 & 1.0 & 46 & 6.1 & 0.4 & 1.6 & 96 & 13 & 14 \\
\hline 21 & 3.6 & 21 & 4.4 & 0.5 & 1.7 & 165 & 20 & 25 \\
\hline 22 & 0.9 & 39 & 3.9 & 0.3 & 1.4 & 83 & 9 & 13 \\
\hline 23 & 0.9 & 23 & 3.2 & 0.2 & 1.2 & 71 & 8 & 13 \\
\hline 24 & 0.7 & 62 & 6.7 & 0.4 & 1.6 & 83 & 9 & 11 \\
\hline 25 & 1.2 & 33 & 5.7 & 0.5 & 1.6 & 95 & 11 & 16 \\
\hline 26 & 1.7 & 41 & 3.9 & 0.2 & 1.1 & 99 & 9 & 15 \\
\hline 27 & 1.0 & 32 & 4.3 & 0.5 & 1.9 & 118 & 13 & 20 \\
\hline 28 & 1.4 & 33 & 5.1 & 0.3 & 1.2 & 81 & 6 & 10 \\
\hline 29 & 1.1 & 44 & 4.5 & 0.4 & 1.3 & 77 & 8 & 13 \\
\hline 30 & 0.8 & 45 & 7.0 & 0.5 & 1.5 & 96 & 12 & 15 \\
\hline 31 & 1.2 & 61 & 4.0 & 0.4 & 1.5 & 125 & 16 & 19 \\
\hline
\end{tabular}




\begin{tabular}{|lllllllll|}
\hline Sample ID & $\mathrm{Cu}$ & $\mathrm{Zn}$ & $\mathrm{Pb}$ & $\mathrm{Cd}$ & $\mathrm{Co}$ & $\mathrm{Fe}$ & $\mathrm{Ni}$ & $\mathrm{Cr}$ \\
\hline 32 & 1.0 & 36 & 5.3 & 0.4 & 1.4 & 70 & 9 & 13 \\
\hline 33 & 0.8 & 32 & 5.3 & 0.3 & 1.1 & 65 & 7 & 9 \\
\hline 34 & 1.0 & 53 & 3.6 & 0.3 & 1.2 & 83 & 9 & 10 \\
\hline 35 & 1.8 & 39 & 5.3 & 0.5 & 1.7 & 292 & 12 & 11 \\
\hline 36 & 0.7 & 45 & 2.9 & 0.3 & 1.1 & 73 & 7 & 11 \\
\hline 37 & 1.5 & 54 & 4.3 & 0.4 & 1.7 & 99 & 10 & 16 \\
\hline 38 & 2.2 & 44 & 3.9 & 0.5 & 2.2 & 220 & 23 & 35 \\
\hline 39 & 1.4 & 64 & 5.1 & 0.4 & 1.4 & 131 & 16 & 22 \\
\hline 40 & 1.7 & 67 & 8.0 & 0.9 & 2.5 & 196 & 24 & 28 \\
\hline Median & 1.3 & 42 & 5.1 & 0.4 & 1.6 & 121 & 14 & 18 \\
\hline Mean & 1.5 & 44 & 5.4 & 0.4 & 1.6 & 164 & 15 & 19 \\
\hline SD & 0.6 & 14 & 1.8 & 0.2 & 0.5 & 225 & 6 & 8 \\
\hline
\end{tabular}

To assess the distribution characteristics of the concentration data, the mean and the median of the log-transformed concentration values (to amplify minor concentration differences and to minimize the influence of a single Fe outlier in the data) across all samples were inspected and compared. A visual comparison is displayed in Fig. 1a as boxplots. It can be seen that, apart from $\mathrm{Ni}$, the boxes are approximately the same size. Additionally, the median line of each box also divided the two halves of a box equally. The latter means our datasets were approximately symmetrical. Furthermore, the distributions of $\mathrm{Cu}$ and $\mathrm{Co}$ appear to be similar and within a larger group of closely related boxes that includes Cd (as shown by dotted enclosure within a larger one). Similarly, the distributions of $\mathrm{Ni}$ and $\mathrm{Cr}$ levels are comparable within a larger closely related group of boxes that includes $\mathrm{Pb}$. These results mean our data were normally distributed and could be explored using most statistical techniques.

\subsection{Characterizing source contamination}

To investigate the heterogeneity of donor samples (or lack thereof), CA was carried out with the data in Table 1. The investigative assumption was that the extent of heavy metal contamination in each beef sample (likely coming from nutrients in animal feed) in a multivariate space should reveal the single or multiple sources of the 40 donor samples, if any, at least at an empirical level. The CA results, presented in Fig. 1b, show that at an arbitrary dissimilarity distance of 6 , the 40 beef samples belong to four different groups A-D (color-coded differently in Fig. 1b). The four groupings delineated are clearly visible in a scatter plot of the same results in Fig. 1c. One sample, Sample ID 12 (Table 1), is a member of its own group (Group D) due to the relatively high level of Fe in the sample. Based on these results, we can speculate that the donor animals came from four sources or that they were raised on distinctively four types of animal feeds. To understand the apparent natural groupings in Fig. 1, the same log-transformed data matrix was subjected to CA in R mode. The results show that not only were there three natural groupings of metals in our sample (at a dissimilarity distance of 5 in Fig. 2a) but that membership of the groupings matches groupings of metals detected by boxplots (Fig. 1a). For confirmation, the same data were also subjected to PCA. The PCA loadings plotted along principal components PC1 and PC2 axes (jointly explaining $98.9 \%$ of variance) are presented in Fig. $2 \mathrm{~b}$. For clarity, the 40 vectors associated with all samples in this multivariate space are not shown since they all aligned along PC2 at the intersection of this axis and PC1. Moreover, because PC2 explains only $0.9 \%$ of the variance here, the alignment of the 40 vectors suggests that the individual variation in metal concentrations had little to do with the sources of the samples. 
The PCA scatter plot shows (i) that Zn and Fe loaded strongly and positively along PC1 and that Ni and Cr loading similarly but weakly and (ii) that $\mathrm{Cd}, \mathrm{Co}$ and $\mathrm{Cu}$ loaded strongly and $\mathrm{Pb}$ loading somewhat similarly and negatively along PC1. These loadings along PC1 (explaining $98.0 \%$ of the variance in the data) means that only these five metals, Fe, Zn, $\mathrm{Cd}, \mathrm{Co}$ and $\mathrm{Cu}$, were responsible collectively to a large extent for the variations observed in the $8 \cdot 40$ raw untransformed data. Because Zn and Fe had the highest concentrations in beef (dotted enclosure in Fig. 2b) while Cd, Cu and Co had the lowest (also enclosed similarly), a positive loading should be interpreted to mean high relative levels of contamination and negative loadings low levels of contaminant. It is understandable then that $\mathrm{Ni}, \mathrm{Cr}$, and $\mathrm{Pb}$ loadings represent here the 'midway' concentrations. These PCA results not only confirm CA findings but also give meaning to the boxplot groupings and sub-groupings in Fig. 1a: that there were four types of donor animals who consumed three broad categories of animal feeds. To pinpoint which of the eight metals was associated with each grouping in Fig. 1a, a generalized pairs plot (Emerson et al., 2013) was used to evaluate the groupings. The pair plot, which displays bivariate combinations of standardized concentrations, is displayed in Fig. 3. For ease of understanding, the following are explanations of the components of this plot. First, the diagonal shows the marginal probability density plots for the metals, and histograms in the bottom row represent the marginal distributions of concentrations, all by beef groupings (color-coded as in Fig. 1b-c). Above the diagonal (top right) are Pearson correlation coefficients (Pearson, 1901) among the metal concentration pairs of metals overall (color coded black) and by groupings. Below the diagonal (on the lower left half of Fig. 2) are scatter plots representing the bivariate relationships between all pairs of the eight metals measured. Second, the far-right column shows the boxplot distribution of each metal concentration by groupings as well. Lastly, the bottom right plot shows the total number of observations in each group as bar charts.

The results (Fig. 3) can be interpreted minimally as follows. Overall, all variables were positively correlated to a different degree in the 40 beef samples as shown by the "Cor" values in black color in the figure. ( $\mathrm{Zn} / \mathrm{Pb}$ and $\mathrm{Zn} / \mathrm{Cu}$ were the exception). The following pairs were particularly highly correlated: $\mathrm{Ni} / \mathrm{Cr}(0.94), \mathrm{Cd} / \mathrm{Co}(0.88), \mathrm{Ni} / \mathrm{Fe}(0.79)$, and $\mathrm{Cr} / \mathrm{Fe}$ (0.72). Moderately correlated were $\mathrm{Co} / \mathrm{Ni}(0.70), \mathrm{Cu} / \mathrm{Ni}(0.69), \mathrm{Cu} / \mathrm{Fe}(0.68), \mathrm{Pb} / \mathrm{Cd}(0.67), \mathrm{Co} / \mathrm{Fe}(0.57), \mathrm{Co} / \mathrm{Cr}(0.55)$ and $\mathrm{Co} / \mathrm{Pb}(0.55)$. The concentration of $\mathrm{Zn}$ was not associated with that of any metal overall, but with $\mathrm{Cd}$ and Co positively and with $\mathrm{Fe}, \mathrm{Ni}$ and $\mathrm{Cr}$ negatively in Group A (also negatively with Cd in Group C). By group, the first group (green, Group A) was associated with high concentrations of all metals except $\mathrm{Cu}$, Group B was associated with low levels of all metals without exceptions, and Group $\mathrm{C}$ was associated with mid-way metal concentrations between high and low. Group D was associated with the highest concentration of Fe recorded in this study. The results in this subsection in general seem to suggest that (i) there were three types of donor animals in our samples with one outlier, (ii) overall, $75 \%$ of beef samples (30/40, Group B) had low levels of contamination in relative terms, (iii) the diet on which the donors were raised had very high levels of Fe and $\mathrm{Zn}$, and (iii) the contaminant pairs $\mathrm{Ni}$ and $\mathrm{Cr}, \mathrm{Cd}$ and $\mathrm{Co}$, Ni and Fe or $\mathrm{Cr}$ and Fe in our Soroti beef samples came from similar sources of contamination.

\subsection{Role of $\mathrm{Pb}, \mathrm{Cd}$, $\mathrm{Ni}$ and $\mathrm{Cr}$ in incremental lifetime cancer risk}

To determine whether the association between the concentrations of the four known carcinogens $\mathrm{Pb}$ and $\mathrm{Cd}$, or $\mathrm{Ni}$ and $\mathrm{Cr}$ (National Toxicology Program, 1996; O. Otim et al., 2019b; US EPA and D. 20460, 2002) revealed by pairs plot (Fig. 3) has any bearing on increased risk of developing cancer over a lifetime, CA (in R mode) was used to evaluate and compare side-by-side the estimated incremental lifetime cancer risk (ILCR, obtained as described in the methods section, Table 2)) in children and adults. The dendrograms generated from the CA results, displayed in Fig. 4a and Fig. 4b, respectively, show similarity in the pattern of groupings between children and adults and the fact that adult results had more variability (by a factor of 30/6, the exposure ratio determined by Kasozi et al. 2021). Clearly, $\mathrm{Ni}$ and $\mathrm{Cr}$ group together, as do Pb and $\mathrm{Cd}$. The presence of this 'natural grouping' was confirmed by PCA (Fig. 4c, children; Fig. 4d, adults), in which Ni and Cr results loaded strongly and positively along PC1 (explaining $99.2 \%$ and $98.7 \%$ of variance in children and adults, respectively), while $\mathrm{Pb}$ and $\mathrm{Cd}$ results loaded strongly and negatively along the same axes. These loadings would suggest that $\mathrm{Ni}$ and $\mathrm{Cr}$ are the main drivers of incremental lifetime cancer risk in both children and adults consuming Soroti beef. PCA appears to have also detected a difference between the contributions of $\mathrm{Ni}$ and $\mathrm{Cd}$ on the one hand and those of $\mathrm{Cr}$ and $\mathrm{Pb}$ on the 
other hand in incremental lifetime cancer risk, at least in adults along PC2 (explaining 1.1\% of variance). The latter may mean that the contributions of $\mathrm{Pb}$ and $\mathrm{Cd}$ to ILCR are identical in children in all ways and not in adults. 
Table 2

Incremental lifetime cancer risk (ILCR, $\times 10^{-3}$ ) estimates for children and adult consumers of Soroti beef

\begin{tabular}{|c|c|c|c|c|c|c|c|c|}
\hline \multirow[b]{2}{*}{ Individual } & \multicolumn{4}{|c|}{ Children } & \multicolumn{4}{|c|}{ Adults } \\
\hline & $\mathrm{Pb}$ & $\mathrm{Cd}$ & $\mathrm{Ni}$ & $\mathrm{Cr}$ & $\mathrm{Pb}$ & $\mathrm{Cd}$ & $\mathrm{Ni}$ & $\mathrm{Cr}$ \\
\hline 1 & 0.02 & 0.07 & 4.98 & 2.91 & 0.08 & 3.52 & 17.79 & 10.41 \\
\hline 2 & 0.01 & 0.03 & 2.90 & 2.00 & 0.04 & 1.62 & 10.38 & 7.14 \\
\hline 3 & 0.01 & 0.01 & 3.97 & 3.35 & 0.03 & 1.37 & 14.20 & 11.97 \\
\hline 4 & 0.01 & 0.03 & 3.16 & 2.54 & 0.03 & 1.51 & 11.30 & 9.08 \\
\hline 5 & 0.01 & 0.03 & 4.55 & 3.48 & 0.04 & 1.62 & 16.27 & 12.43 \\
\hline 6 & 0.01 & 0.03 & 4.18 & 3.14 & 0.04 & 1.71 & 14.92 & 11.21 \\
\hline 7 & 0.01 & 0.03 & 5.29 & 4.25 & 0.03 & 1.49 & 18.92 & 15.20 \\
\hline 8 & 0.01 & 0.01 & 3.19 & 3.09 & 0.03 & 1.31 & 11.39 & 11.03 \\
\hline 9 & 0.01 & 0.03 & 4.34 & 3.56 & 0.04 & 1.73 & 15.52 & 12.71 \\
\hline 10 & 0.01 & 0.01 & 2.38 & 1.97 & 0.04 & 1.83 & 8.49 & 7.06 \\
\hline 11 & 0.01 & 0.08 & 5.08 & 3.54 & 0.05 & 2.38 & 18.17 & 12.66 \\
\hline 12 & 0.02 & 0.05 & 4.52 & 2.80 & 0.06 & 2.72 & 16.15 & 10.02 \\
\hline 13 & 0.00 & 0.03 & 4.78 & 3.73 & 0.02 & 0.78 & 17.07 & 13.34 \\
\hline 14 & 0.01 & 0.04 & 3.85 & 2.72 & 0.04 & 1.71 & 13.75 & 9.70 \\
\hline 15 & 0.01 & 0.03 & 3.01 & 2.16 & 0.03 & 1.38 & 10.76 & 7.70 \\
\hline 16 & 0.02 & 0.09 & 3.64 & 2.37 & 0.06 & 2.77 & 13.00 & 8.47 \\
\hline 17 & 0.02 & 0.05 & 2.70 & 1.91 & 0.06 & 2.61 & 9.65 & 6.84 \\
\hline 18 & 0.01 & 0.04 & 1.89 & 1.39 & 0.05 & 2.21 & 6.74 & 4.96 \\
\hline 19 & 0.02 & 0.03 & 1.19 & 0.82 & 0.05 & 2.45 & 4.25 & 2.94 \\
\hline 20 & 0.01 & 0.04 & 2.60 & 1.69 & 0.04 & 1.95 & 9.29 & 6.02 \\
\hline 21 & 0.01 & 0.05 & 3.89 & 2.91 & 0.03 & 1.41 & 13.90 & 10.39 \\
\hline 22 & 0.01 & 0.03 & 1.72 & 1.56 & 0.03 & 1.25 & 6.14 & 5.58 \\
\hline 23 & 0.01 & 0.02 & 1.57 & 1.60 & 0.02 & 1.05 & 5.60 & 5.71 \\
\hline 24 & 0.01 & 0.04 & 1.78 & 1.31 & 0.05 & 2.15 & 6.37 & 4.68 \\
\hline 25 & 0.01 & 0.05 & 2.26 & 1.87 & 0.04 & 1.85 & 8.06 & 6.68 \\
\hline 26 & 0.01 & 0.02 & 1.80 & 1.76 & 0.03 & 1.27 & 6.43 & 6.31 \\
\hline 27 & 0.01 & 0.04 & 2.54 & 2.40 & 0.03 & 1.39 & 9.06 & 8.57 \\
\hline 28 & 0.01 & 0.03 & 1.23 & 1.19 & 0.04 & 1.63 & 4.39 & 4.26 \\
\hline 29 & 0.01 & 0.03 & 1.57 & 1.53 & 0.03 & 1.46 & 5.61 & 5.48 \\
\hline
\end{tabular}




\begin{tabular}{|lllllllll|}
\hline \multicolumn{7}{l}{ Children } & \multicolumn{7}{c|}{ Adults } \\
\hline 30 & 0.01 & 0.04 & 2.46 & 1.73 & 0.05 & 2.26 & 8.78 & 6.17 \\
\hline 31 & 0.01 & 0.03 & 3.12 & 2.24 & 0.03 & 1.30 & 11.15 & 7.99 \\
\hline 32 & 0.01 & 0.04 & 1.72 & 1.49 & 0.04 & 1.70 & 6.13 & 5.32 \\
\hline 33 & 0.01 & 0.03 & 1.30 & 1.08 & 0.04 & 1.71 & 4.64 & 3.85 \\
\hline 34 & 0.01 & 0.03 & 1.73 & 1.21 & 0.03 & 1.16 & 6.20 & 4.33 \\
\hline 35 & 0.01 & 0.05 & 2.30 & 1.27 & 0.04 & 1.71 & 8.22 & 4.54 \\
\hline 36 & 0.01 & 0.03 & 1.35 & 1.26 & 0.02 & 0.92 & 4.82 & 4.51 \\
\hline 38 & 0.01 & 0.04 & 2.06 & 1.92 & 0.03 & 1.38 & 7.37 & 6.88 \\
\hline 39 & 0.01 & 0.05 & 4.56 & 4.16 & 0.03 & 1.25 & 16.30 & 14.87 \\
\hline 40 & 0.01 & 0.04 & 3.21 & 2.61 & 0.04 & 1.65 & 11.49 & 9.32 \\
\hline
\end{tabular}

To assess whether $\mathrm{Cr}$ and $\mathrm{Ni}$ in this context are the major drivers of incremental lifetime cancer risk in children and adults, the ILCR data were reevaluated by CA in Q mode. As before, the dominant groupings of beef samples were identified based on dissimilarity distances in a dendrogram (Fig. 5). The results show the presence of three major groupings $X, Y$ and $Z$ at an arbitrary cutoff dissimilarity value of 9 . The beef clusters were well separated by a balanced count of samples in each group and a larger $F$-statistic describing between-group separation in the dissimilarity values $(F=155.9, p<0.001)$. Notably, Sample ID 12 - the sample with very high Fe content - was absorbed into Group X, and the entire Group A originally present in Fig. $1 \mathrm{~b}$ - has been assimilated into a single large group, Group Z. These results suggest that there are also three types of ILCRs based on samples.

To confirm this CA finding and to assess whether $\mathrm{Cr}$ and $\mathrm{Ni}$ - and not $\mathrm{Pb}$ and $\mathrm{Cd}-$ are the major drivers of incremental lifetime cancer risk in children in this study, the same CA data were also evaluated by PCA in Q mode. The results, displayed in Fig. 6, show good separation of the three sample groups identified by CA, albeit incomplete since the two methods are based on different underlying principles. The metals associated with the groups are also shown as vectors. The cumulative variance for the PC1 and PC2 axes explained $100 \%$ of the variation in the metal data between the beef samples (i.e., all the differences in beef samples are accounted for by PC1 and PC2). By inspection, the axis PC1 described a gradient between beef samples that differed in which metals were associated with Group X (red) and Group Y (green). Positive loadings on the PC1 axis were associated with $\mathrm{Cr}$ and $\mathrm{Ni}$, and negative loadings were not associated with any of the four metals. Similarly, positive loadings on PC2 were associated with $\mathrm{Cr}$ (and 12 of 19 samples from Group Z), and negative loadings were associated very strongly with $\mathrm{Ni}$ (and all Group X samples) and very weakly with $\mathrm{Pb}$ and $\mathrm{Cd}$. For each group, PC1 separated Group X (red) from Group Y (green). Group Y and seven beef samples from Group Z were not associated with any of the four metal ILCR values. These PCA results not only confirm the CA findings above but also suggest (i) that $\mathrm{Cr}$ and $\mathrm{Ni}$ - of the four metals whose cancer slope factors are somewhat known - are the main drivers of the limited health concern here, (ii) that the impact of $\mathrm{Cr}$ and $\mathrm{Ni}$ on Soroti beef consumers were most likely not identical, and (iii) that $\mathrm{Pb}, \mathrm{Cd}$, $\mathrm{Ni}$ and $\mathrm{Cr}$ had no role in incremental lifetime cancer risk in 53\% of our samples (Fig. 6: 16/40, Group Y; 5/40, Group Z).

\section{Study Limitations}


The associations observed in this study have not been observed in beef in Uganda before to our knowledge. Additionally, we believe that the methodologies employed here have not previously been applied in similar studies in beef in Uganda. As such, similar studied are still needed for comparison.

In collecting the 40 beef samples, pertinent information such as sources and the ages of the donor animals, their physical characteristics and how they were raised, the metal contents of their feed, the soil upon which the feeds were cultivated and water available to the donors were unavailable. Knowing these pieces of information would have perhaps aided in pinpointing sources of metal contamination and their entrance into the food chain and subsequent bioaccumulation. Furthermore, results of elemental analysis here are reported in wet-weight; the usual practice is to report in a dry-weight basis to eliminate differences in moisture content. In the absence of these pieces of information and the lack of reporting measurements in dry-weight, this should be taken as a first into understanding the nature of beef pollution in Soroti and, by extrapolation, in Uganda.

\section{Conclusion}

In this paper, the unique fingerprints of eight heavy metals in 40 contaminated beef samples were exploited to develop a multivariate framework for perhaps understanding the extent of food contamination in Soroti District of Uganda and the country as a whole. The extent of contamination in these samples followed the order $\mathrm{Fe}>\mathrm{Zn}>>\mathrm{Ni}, \mathrm{Cr}>\mathrm{Pb}>\mathrm{Cu}, \mathrm{Co}>\mathrm{Cd}$. On the basis of the metal content of 40 beef samples, we have shown that there are at least three distinct characteristics of beef consumed in the area. This distinction, to the minimum, points to perhaps three major categories of forage or feedlots used to raise donor animals, or at least the nutrients consumed by the donors. If the age of the animals and their health status are not factored in, the distinction suggests that (i) there were three types of donor animals in our samples with one outlier, (ii) overall, $75 \%$ of beef samples (30/40, Group B) had low levels of contamination in relative terms, (iii) the diet on which the donors were raised had very high levels of $\mathrm{Fe}$ and $\mathrm{Zn}$, and (iii) the contaminant pairs $\mathrm{Ni}$ and $\mathrm{Cr}$, $\mathrm{Cd}$ and $\mathrm{Co}, \mathrm{Ni}$ and $\mathrm{Fe}$ or $\mathrm{Cr}$ and $\mathrm{Fe}$ in our Soroti beef samples came from similar sources of contamination. The incremental risk of children or adults developing cancer over a lifetime, the impact of which is relatively identical, was also found to fall into three categories, two of which are separately driven by the presence of chromium or nickel. The driver for the third category was missing in our analysis.

More studies are needed to increase the number of heavy metals with known cancer slope factors to allow their inclusion in cancer risk studies. To date, only $\mathrm{Pb}, \mathrm{Cr}$ and $\mathrm{As}$ have been included in such studies. Also required are more studies to gather as much data as one would need to develop 'food contamination study' templates for use in underdeveloped countries with access to rudimentary laboratory setup such as Uganda.

\section{Declarations}

Author contributions: KIK conceptualized the study, KIK and $O O$ designed the work, KIK, JE, KM, GZ, ETA, RM, AT, AA, RSB, and GEB conducted data acquisition, while KIK, EOO, $O O$ conducted the analysis and interpreted the data. KIK, EOO and $\mathrm{OO}$ drafted the initial manuscript, while KIK, EOO, JE, KM, GZ, ETA, RM, AT, RSB, AA, OO, and GEB revised it critically for intellectual content. All authors approved the final version submitted for publication and are accountable for all aspects of the work.

Conflict of interests: The authors declare no conflicts of interest.

Funding: The study was partially supported by the administration of Busitema University.

Data availability statement: Data files used in the study can be found at https://figshare.com/s/231bb252ceae87d86d12. 
Acknowledgment: This research was partially supported by the administration of Busitema University, and critical comments shared by colleagues who are not on the manuscript during conceptualization of the study are acknowledged. This work was supported by Taif University Researchers Supporting Program (project number: TURSP-2020/269), Taif University, Saudi Arabia.

\section{References}

Alam, M., Khan, M., Khan, A., Zeb, S., Khan, M. A., ul Amin, N., et al. (2018). Concentrations, dietary exposure, and human health risk assessment of heavy metals in market vegetables of Peshawar, Pakistan. Environmental Monitoring and Assessment, 190(9), 505, https://doi.org/10.1007/s10661-018-6881-2

Anna, P., Barbara, G., \& Emillia, R. (2019). Heavy metal content in the green fodder of field pea/oat mixtures destined for cattle feed. Environmental Monitoring and Assessment, 191, 680, https://doi.org/10.1007/s10661-019-7874-5

Anon. (1990). Chromium, nickel and welding. IARC Monographs on the Evaluation of Carcinogenic Risks to Humans, 49, $1-648$.

ATSDR. (2019). The ATSDR's Substance priority list 2019. Agency for Toxic Substances and Disease Registry. https://www.atsdr.cdc.gov/spl/\#2019spl. Accessed 14 January 2021.

Bamuwamye, M., Ogwok, P., \& Tumuhairwe, V. (2015). Cancer and non-cancer risks associated with heavy metal exposures from street foods: evaluation of roasted meats in an urban setting. Journal of Environment Pollution and Human Health, 3(2), 24-30. https://doi.org/10.12691/jephh-3-2-1

Beniamini, Y. (1988). Opening the box of a boxplot. American Statistician. https://doi.org/10.1080/00031305.1988.10475580

Boutros, P. C., \& Okey, A. B. (2005). Unsupervised pattern recognition: An introduction to the whys and wherefores of clustering microarray data. In Briefings in Bioinformatics. https://doi.org/10.1093/bib/6.4.331

Chen, Q. Y., DesMarais, T., \& Costa, M. (2019). Metals and mechanisms of carcinogenesis. Annual Review of Pharmacology and Toxicology, 59(1), 537-554. https://doi.org/10.1146/annurev-pharmtox-010818-021031

Emerson, J. W., Green, W. A., Schloerke, B., Crowley, J., Cook, D., Hofmann, H., \& Wickham, H. (2013). The generalized pairs plot. Journal of Computational and Graphical Statistics, 22(1), 79-91. https://doi.org/10.1080/10618600.2012.694762

Fotakis, C., \& Zervou, M. (2016). NMR metabolic fingerprinting and chemometrics driven authentication of Greek grape marc spirits. Food Chemistry. https://doi.org/10.1016/j.foodchem.2015.10.002

Gergen, I., \& Harmanescu, M. (2012). Application of principal component analysis in the pollution assessment with heavy metals of vegetable food chain in the old mining areas. Chemistry Central Journal. https://doi.org/10.1186/1752-153X-6156

Gewers, F. L., Ferreira, G. R., de Arruda, H. F., Silva, F. N., Comin, C. H., Amancio, D. R., \& Costa, L. da F. (2018). Principal Component Analysis: A Natural Approach to Data Exploration. 1-31. http://arxiv.org/abs/1804.02502

Grace, D. (2015). Food safety in low and middle income countries. In International Journal of Environmental Research and Public Health. https://doi.org/10.3390/ijerph120910490

Hammer, Ø., Harper, D. A. T., \& Ryan, P. D. (2001). Past: Paleontological statistics software package for education and data analysis. Palaeontologia Electronica. https://palaeo-electronica.org/2001_1/past/issue1_01.htm. Accessed 14 January 
2021.

Kaaya, A.K., Msanya, B.M., \& Mrervla, J.P. (1994), Soils and land evaluation of part of the Sokoine University of Agriculture Farm (Tanzania) for some crops under rainfed conditions. African Study Monographs, 15, 97-117, https://repository.kulib.kyoto-u.ac.jp/dspace/bitstream/2433/68116/1/ASM_15_97.pdf. Accessed 14 January 2021.

https://www.scirp.org/journal/paperinformation.aspx?paperid=88438\#return45

Kamunda, C., Mathuthu, M., \& Madhuku, M. (2016). Health Risk Assessment of Heavy Metals in Soils from Witwatersrand Gold Mining Basin , South Africa. https://doi.org/10.3390/ijerph13070663

Kasozi, K. I., Namubiru, S., Kamugisha, R., Eze, E. D., Tayebwa, D. S., Ssempijja, F., Okpanachi, A. O., Kinyi, H. W., Atusiimirwe, J. K., Suubo, J., Fernandez, E. M., Nshakira, N., \& Tamale, A. (2019). Safety of drinking water from primary water sources and implications for the general public in Uganda. Journal of Environmental and Public Health, 2019, 1-12. https://doi.org/10.1155/2019/7813962

Kasozi, K. I., Natabo, P. C., Namubiru, S., Tayebwa, D. S., Tamale, A., \& Bamaiyi, P. H. (2018). Food safety analysis of milk and beef in southwestern Uganda. Journal of Environment and Public Health, 2018, 1-7.

https://doi.org/10.1155/2018/1627180

Kasozi, K. I., Hamira, Y., Zirintunda, G., Al-Rashed, S., Altalbawy, F. M. A., Ekou, J., Tamale, A., Matama, K., Ssempijja, F., Muyinda, R., Kawooya, F., Pius, T., Kisakye, H., Bogere, P., Matovu, H., Omadong, L., Etiang, P., Mbogua, J., Ochieng, J. J., Osuwat, L. O., Mujinya, R., Batiha, G. E-S., \& Otim, O. (2021). Descriptive analysis of heavy metals content of beef from eastern Uganda and their safety for public consumption. Frontiers in Nutrition, 8, 592340.

https://doi.org/10.3389/fnut.2021.592340

Kim, H. S., Kim, Y. J., \& Seo, Y. R. (2015). An overview of carcinogenic heavy metal: molecular toxicity mechanism and prevention. Journal of Cancer Prevention, 2O(4), 232-240. https://doi.org/10.15430/JCP.2015.20.4.232

Kimera, F., Sewilam, H., \& Imam, E. (2018). Economic benefits of supplemental irrigation in Uganda. Agricultural Sciences, 9(11). https://www.scirp.org/journal/paperinformation.aspx?paperid=88438\#return45. Accessed 14 January 2021.

National Toxicology Program. (1996). NTP Toxicology and carcinogenesis studies of nickel oxide (CAS No. 1313-99-1) in F344 Rats and B6C3F1 mice (Inhalation Studies). National Toxicology Program Technical Report Series, 451, 5-317. http://www.ncbi.nlm.nih.gov/pubmed/12594524. Accessed 14 January 2021.

Nkansah, M. A., \& Ansah, J. K. (2014). Determination of Cd , Hg , As , Cr and Pb levels in meat from the Kumasi Central Abattoir. International Journal of Scientific and Research Publications. http://www.ijsrp.org/research-paper-0814/ijsrpp3215.pdf. Accessed 14 January 2021.

Nkwunonwo, U. C., Odika, P. O., \& Onyia, N. I. (2020). A Review of the health implications of heavy metals in food chain in Nigeria. The Scientific World Journal, 2020, 6594109. https://doi.org/10.1155/2020/6594109

Odoh, R., Ogah, E., \& Ushie, O. A. (2016). Determination of some heavy metal profiles in meat of domesticated animals in the vicinity of Kaduna South industrial area, Nigeria. FUW Trends in Science \& Technology Journal, 1(2), 337-343. www.ftstjournal.com. Accessed 14 January 2021.

Otim, E. O., Chen, I. R., \& Otim, O. (2019a). Applying multivariate analysis to characterize waragi spirits from Acoli, Uganda, by their metal contents. Heliyon, 5(4), e01417. https://doi.org/10.1016/j.heliyon.2019.e01417 
Otim, O., Juma, T., \& Otunnu, O. (2019b). Assessing the health risks of consuming 'sachet' alcohol in Acoli, Uganda. PLOS ONE, 14(2), e0212938. https://doi.org/10.1371/journal.pone.0212938

Pearson, K. (1901). LIII. On lines and planes of closest fit to systems of points in space. The London, Edinburgh, and Dublin Philosophical Magazine and Journal of Science. https://doi.org/10.1080/14786440109462720

R Core Team. (2019). R: A language and environment for statistical computing. v3.6.3. Vienna, Austria. https://www.rproject.org/. Accessed 14 January 2021.

Singh, R., Gautam, N., Mishra, A., \& Gupta, R. (2011). Heavy metals and living systems: An overview. Indian Journal of Pharmacology, 43(3), 246. https://doi.org/10.4103/0253-7613.81505

Uganda National Bureau of Standards. (2018). Cattle feeds-specifications. DUS DEAS, First edit, 1-25. https://members.wto.org/crnattachments/2018/TBT/UGA/18_1594_00_e.pdf. Accessed 14 January 2021.

US EPA. (2001). Risk assessment guidance for superfund (RAGS) Volume III - Part A: Process for conducting probabilistic risk assessment, Appendix B. Office of Emergency and Remedial Response U.S. Environmental Protection Agency, III(December), 1-385. http://www.epa.gov/region9/toxic/noa/clearcreek/pdf/CCMAexposure-risk assessmentfactsheet. Accessed 14 January 2021.

US EPA. (2008). U . S . EPA releases exposure and risk assessment for clear creek management area. United States Environmental Protection Agency, Region 9. http://www.epa.gov/region9/toxic/noa/clearcreek/pdf/CCMAexposure-risk assessmentfactsheet. Accessed 14 January $2021 .$.

US EPA and D. 20460. (2002). Evaluation of the potential carcinogenicity of lead and lead compounds: in support of reportable quantity adjustments pursuant to CERCLA section 102: EPA/600/8-89/045A (NTIS PB89181366). EPA-822-B00025. United States Environmental Protection Agency, Washington, DC., 1-114.

https://cfpub.epa.gov/si/si_public_record_report.cfm?

Lab=NCEA\&TIMSType=\&count=10000\&dirEntryld=39811\&searchAll=\&showCriteria $=2 \&$ simpleSearch $=0 \&$ startIndex $=30001$ . Accessed 14 January $2021 .$.

USEPA. (1998). Toxicological review of hexavalent chromium. National Center for Environmental Assessment. US EPA Website Http://Water.Epa.Gov/Drink/Contaminants/Index.Cfm, August(18540).

https://cfpub.epa.gov/ncea/iris_drafts/AtoZ.cfm. Accessed 14 January 2021..

Wiley, J. F., \& Pace, L. A. (2015). Chapter 8: Descriptive statistics and exploratory data analysis. In Beginning R (pp. 7380). Apress. https://doi.org/10.1007/978-1-4842-0373-6_8

Yabe, J., Ishizuka, M., \& Umemura, T. (2010). Current levels of heavy metal pollution in Africa. The Journal of Veterinary Medical Science / the Japanese Society of Veterinary Science, 72(10), 1257-1263. https://doi.org/10.1292/jvms.10-0058

Zwick, W. R., \& Velicer, W. F. (1982). Factors influencing four rules for determining the number of components to retain. Multivariate Behavioral Research. https://doi.org/10.1207/s15327906mbr1702_5

\section{Figures}




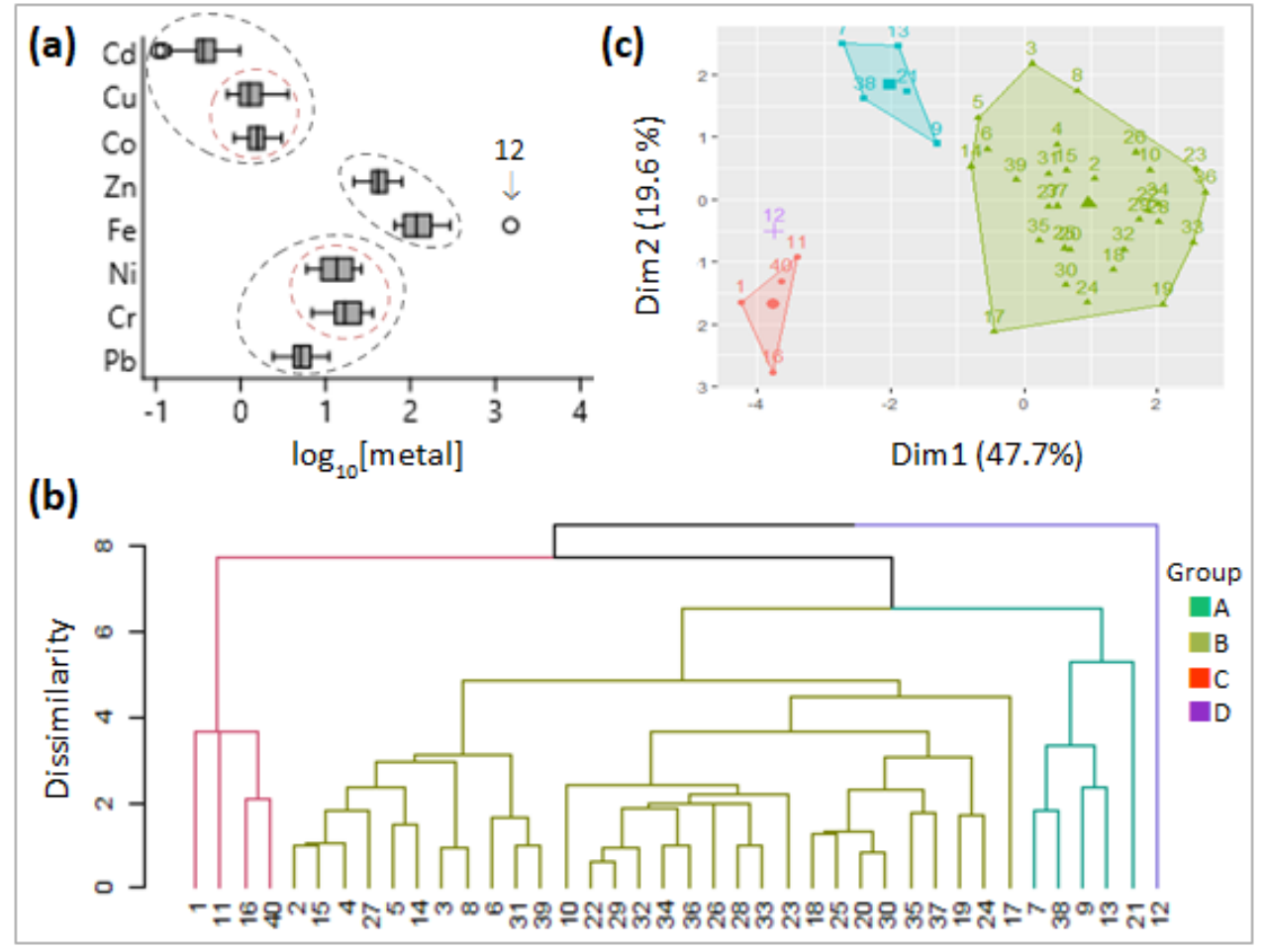

\section{Figure 1}

(a) Boxplots showing the distribution of metal levels in the 40 beef samples. Concentrations were log-transformed to minimize the impact of high Fe levels on the shape of the plot. An outlier with Sample ID 12 is indicated. (b) Dendrogram showing four groupings of Soroti beef samples based on raw levels of $\mathrm{Cu}, \mathrm{Zn}, \mathrm{Pb}, \mathrm{Cd}, \mathrm{Co}, \mathrm{Fe}, \mathrm{Ni}$ and $\mathrm{Cr}$ contamination in 40 samples (Table 1). Number of samples per group: A, 5 samples; B, 30; C, 4; and D, 1 sample. (c) Scatter plots of data in (b) showing the clear distinctiveness of the four groupings of beef samples. Notice in (b) and (c) that Sample ID 12 (Table 1 ) is the only member of its group.
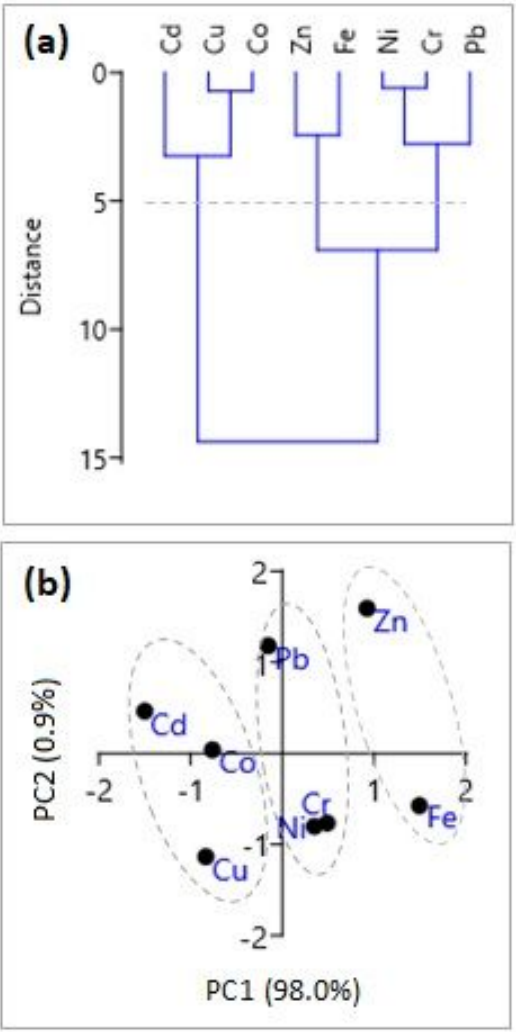


\section{Figure 2}

Results of exploratory analysis to determine if there are natural associations among the metals in all 40 beef samples. (a) The clustering of metals by CA (cophenetic correlation coefficients: 0.698 ) showing that at a dissimilarity distance of 5 (0 meaning identical concentration characteristics), the metals form three clusters: $\mathrm{Cd}, \mathrm{Cu}$ and $\mathrm{Co} ; \mathrm{Zn}$ and Fe; and $\mathrm{Ni} \mathrm{Cr}$ and $\mathrm{Pb}$. (b) PCA scatter plot of the first versus the second principal axes using eigenvalue scale confirming the observed grouping in (a). CA and PCA are statistical techniques with very different underlying principles. Concentration data were log-transformed before use.

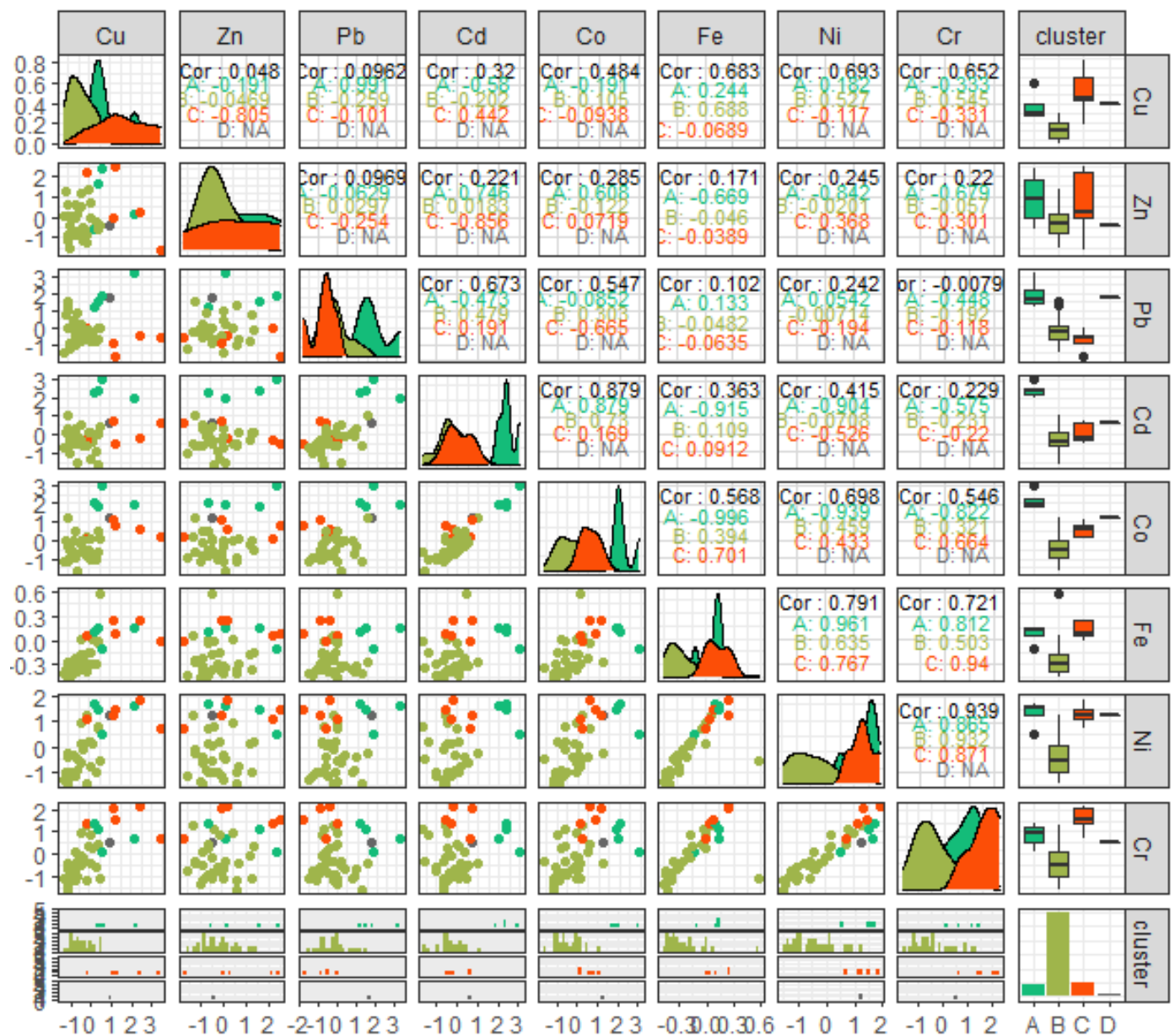

\section{Figure 3}

A generalized pairs plot displaying paired combinations of beef sample numbers and standardized heavy metal concentration data. The measures of pairwise correlation are presented as plots below the diagonal and as Pearson's $r$ values above the diagonal. The sample groupings and color coding are derived from the dendrogram in Figure $1 \mathrm{~b}$. 


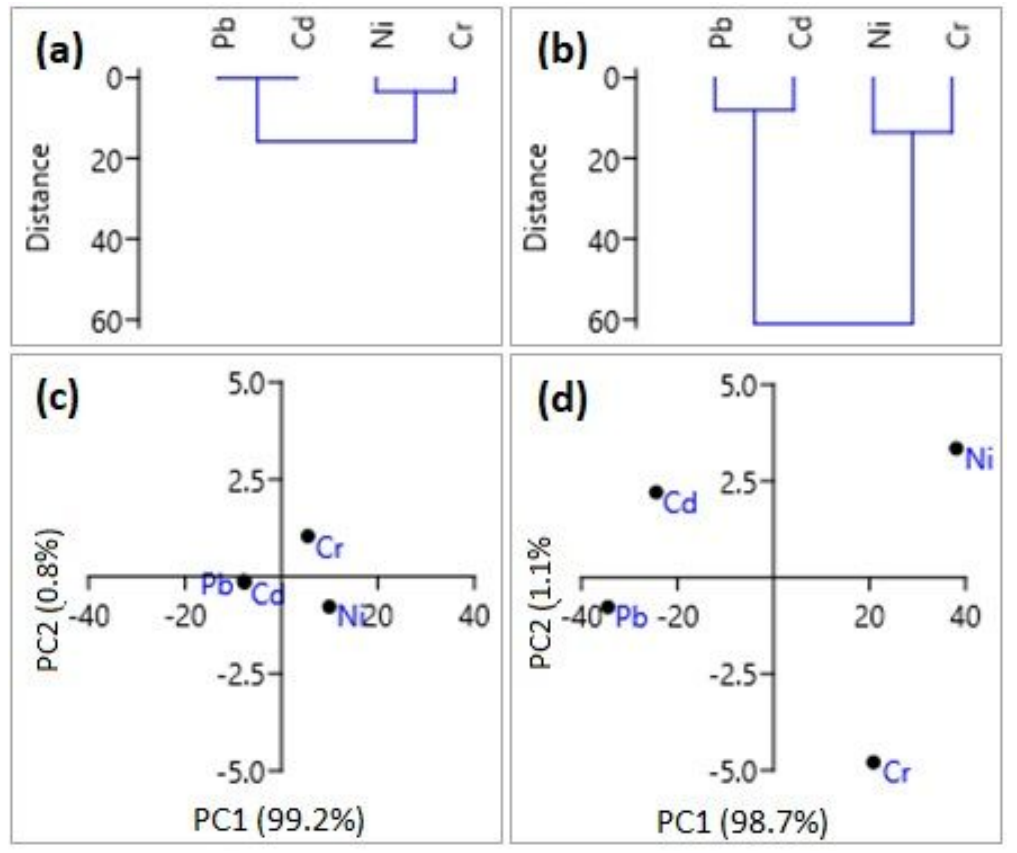

Figure 4

Relative ILCR in children $(\mathrm{a}, \mathrm{c})$ and adults $(\mathrm{b}, \mathrm{d})$ arising from consuming $\mathrm{Pb}, \mathrm{Cd}, \mathrm{Ni}$ and $\mathrm{Cr}$ in sampled beef collected from Soroti. Comparatively, the nature of ILCR is identical in both children and adults, but the extent is larger in adults (compare (a) with (b)). This is confirmed by the results displayed and (c) and (d), which suggest that at least $99 \%$ of the nature of contamination is identical even though there appears to be a $1 \%$ reversal of the order along the second axis. Cophenetic correlation coefficients (Ward's method): 0.963 (a) and 0.933 (b).

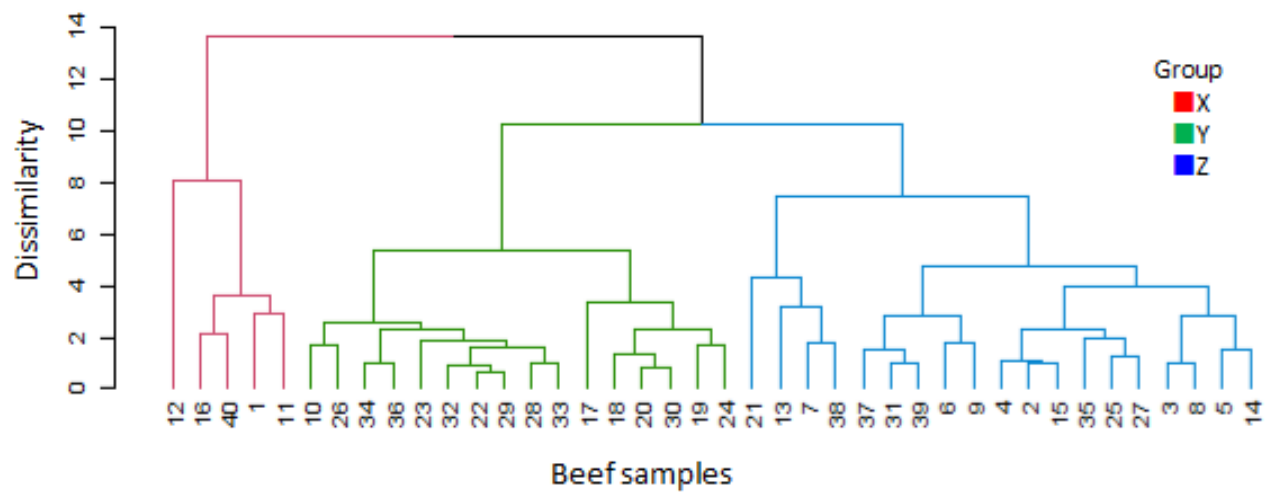

\section{Figure 5}

Dendrogram showing clusters based on a dissimilarity matrix of Euclidean distances for ILCR values in children. The tree was cut arbitrarily at a dissimilarity distance of nine (9) to identify sample groupings within which relative ILCR values were similar. There are actually three major groups of ILCR values: Group X (red, 5 samples); Group Y (green, 16 samples); and Group Z (blue, 19 samples). 


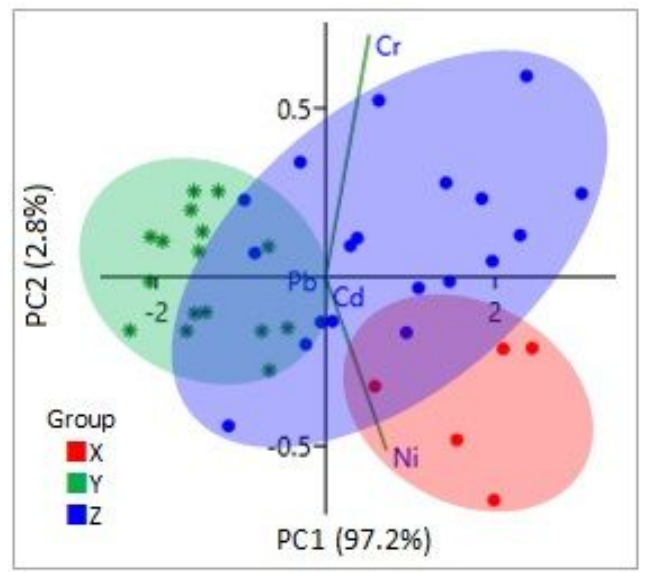

Figure 6

A biplot of PCA results showing $\mathrm{Ni}$ and $\mathrm{Cr}$ as the two of four metals with known cancer response factors playing prominent roles in the potential development of cancer from consuming beef in the X (red) and Z (blue) sub-groups of the community studied, respectively. $\mathrm{Pb}$ and $\mathrm{Cd}$, having values close to the origin, do not play much of a role in developing cancer by this model. This result also suggests that $\mathrm{Pb}, \mathrm{Cr}, \mathrm{Cd}$ and $\mathrm{Ni}$ levels in beef alone are indequate to explain the risk observed in the $Y$ (green) subgroup. 